\title{
Reading Processes and Parenting Styles
}

\author{
Rui Manuel Carreteiro' ${ }^{1}$ João Manuel Justo ${ }^{2}$. \\ Ana Paula Figueira ${ }^{3}$
}

(C) Springer Science+Business Media New York 2015

\begin{abstract}
Home literacy environment explains between 12 and $18.5 \%$ of the variance of children's language skills. Although most authors agree that children whose parents encourage them to read tend to develop better and earlier reading skills, some authors consider that the impact of family environment in reading skills is overvalued. Probably, other variables of parent-child relationship, like parenting styles, might be relevant for this field. Nevertheless, no previous studies on the effect of parenting styles in literacy have been found. To analyze the role of parenting styles in the reading processes of children. Children's perceptions of parenting styles contribute significantly to the explanation of statistical variance of children's reading processes. 110 children ( 67 boys and 43 girls), aged between 7 and 11 years $(M=9.22$ and $\mathrm{SD}=1.14$ ) from Portuguese schools answered to a socio-demographic questionnaire. To assess reading processes it was administered the Portuguese adaptation (Figueira et al. in press) of Bateria de Avaliação dos Processos Leitores-Revista (PROLEC-R). To assess the parenting styles Egna Minnen av Barndoms Uppfostran-parents (EMBU-P) and EMBU-C (children version) were administered. According to multiple hierarchical linear regressions, individual factors contribute to explain all reading tests of PROLEC-R, while family factors contribute to explain most of these tests. Regarding parenting styles, results evidence the explanatory power about grammatical structures, sentence comprehension and listening. Parenting styles have an important role in the explanation of higher reading processes (syntactic and semantic) but not in lexical processes, focused by main theories concerning dyslexia.
\end{abstract}

Keywords Reading $\cdot$ Parenting styles $\cdot$ Children $\cdot$ Dyslexia

Rui Manuel Carreteiro rui.carreteiro@inpn.pt

1 National Institute of Psychology and Neurosciences, Lisbon, Portugal

2 Faculty of Psychology, University of Lisbon, Lisbon, Portugal

3 Faculty of Psychology and Educational Sciences, University of Coimbra, Coimbra, Portugal 


\section{Introduction}

Reading Processes (RP) are the key to decoding written words. Due to its prevalence and profound impact in people's life, Reading Disorders (RD) are among the most studied impairments, although with low consensus. Most authors (Castles and Coltheart 2004; Vellutino et al. 2004) consider the phonological deficit as the main cause of RD, but there are many alternative explanations.

According to Gallagher et al. (2000), one of main limitations of these studies concerns the fact that most of them include subjects with RD properly established: since the relationship between literacy and phonological skills is reciprocal (Morais et al. 1979), it is likely that phonological deficits observed in RD subjects were caused by RD. Most authors (e.g., Dehaene 2007) agree that in the interface between nature and culture, our abilities to read are due to several factors where a good teaching seems to be as important as the presence of neuronal, visual or phonological processes correctly interconnected. According to Fletcher (2009), dyslexia depends, among others, of environmental factors (e.g., socio-economic factors, education, etc.) and psychosocial/behavioral factors (e.g., motivation, attention and anxiety).

Several studies suggest that parent-child relationship, in particular Parenting Styles (PS), are related to children and youth's performance (Areepattamannil 2010; Chan and Koo 2010; Cripps and Zyromski 2009; Ewnetu and Fisseha 2008; Jacob 2011; Jeynes 2007; Mendoza 2013; Williams 2008; Zellman and Waterman 1998). According to previous studies, more adaptive PS promote a better performance when compared with less adaptive PS. Nevertheless, we couldn't find previous studies about the particular effect of PS in RP.

Salyer et al. (1991) recognize that, when associated with learning disabilities or cognitive factors, psychological factors are easily seen as secondary and due to frustration or to manifestation of the dysfunction. However, according to Green (1989), the diversity and complexity of learning disabilities requires a multidimensional analysis that should consider, at least, individual differences (genetic, psychophysiological, cognitive, emotional, and behavioural), social network (family, relationship with peers, parental working context) and socioeconomic/cultural/political context.

Although not much is known about the relation between PS and RP, it is clear that parents influence children's reading skills (e.g., Sutherland 1975, cited in Harmer and Alexander 1978). More specifically, parental attitudes towards reading seem to influence the development of children's reading skills (Della-Piana et al. 1968 and Goldman and Barclay 1974, both cited by Harmer and Alexander 1978).

Furthermore, several studies have also established a relationship between home literacy environment and preschool language skills, indicating that home literacy environment contributes to the explanation of $12-18.5 \%$ of the variance of language skills in 4 years old children (Senechal 2000; Payne et al. 1994). According to Fitzgerald et al. (1991), regardless of their literacy levels, parents who show a positive attitude towards an emergent literacy and read to their children are strong predictors for literacy development.

Analyzing the relationship between reading styles and the development of reading skills, several studies suggest that parents who describe pictures and ask questions to children like "what...?" (requiring little thought by the child) boost the development of the analysis of letters and letter-words connection. Moreover, parents who use a more comprehensive style, asking more reflexive questions, stimulate a larger vocabulary and higher levels of comprehension (Reese and Cox 1985). 
According to Kissinger (2004), when parents are active readers, their children have a great interest in reading as well and also begin to read sooner than average. For this author, the particular relationship that parents establish with their children directly affects children's motivation and consequently, their literacy. Although according to Bus et al. (1995), the parents-children's joint reading is the primary determinant of emergent literacy, from a meta-analysis, Scarborough and Dobrich (1994) argue that home literacy environment is overvalued.

\section{Aim and Hypothesis}

Al-Yagon (2007) notes that the pattern of father-mother relationship is very important in children with RD since (a) these variables can work as risk or protective factors and (b) because children with RD are more prone to behavioural problems. Moreover, in general, during infancy, the parent-children relationship is one of the most important factors. Therefore, the main general aim of this research is to analyze the role of PS in the emergence of RD (assessed trough RP' performance).

According to this goal and previous literature review, it seems possible to propose the following hypothesis: Children's perceptions of PS contribute to the explanation of the statistical variance of children's RP. This hypothesis is based on the research of several authors (Al-Yagon 2007; Bus et al. 1995; Ferreiro and Teberosky 1986; Fitzgerald et al. 1991; Harmer and Alexander 1978; Kissinger 2004; Morais 1994; Payne et al. 1994; Reese and Cox 1985; Senechal 2000) who advocate an active role of family environment in literary skills' development.

Although we recognize that there is a growing consensus about RD being due to subjects' phonological changes, recent studies (e.g., Pacheco et al. 2014) emphasize the multifactorial features of RD, besides the fact that eventually this pattern may not be applied to all the cases of children with RD. Also, despite the strong genetic and neurological correlations with dyslexia, it would not be a novelty that neurological changes could underlie parental attitudes. For example, a study conducted by Narita et al. (2010) showed a correlation between parental care/parental overprotection and volume reduction in gray matter as well as in dorsomedial prefrontal cortex.

\section{Methods}

\section{Participants}

In this study participants were 110 children (67 boys and 43 girls), aged from 7 to 11 years $(\mathrm{M}=9.22$ and $\mathrm{SD}=1.14)$, from several Portuguese learning institutions (North, Central, South, Madeira and Azores). Written informed consents were obtained from both parents and learning institutions.

All participants met the following general inclusion criteria: (a) age between 7 and 11 years; (b) intellectual level greater or equal than the expected for their age, according to CPM standards for Portuguese population; (c) absence of neurological disorders based on clinical history and (d) absence of visual or hearing problems that could interfere with the ability of hearing or reading.

The choice of the age range took into account cognitive development and personality issues: it was decided not to include children with $<6$ years old, as this age coincides with 
the beginning of schooling, avoiding misunderstandings between the lack of knowledge and the lack of skills for reading. The range from 7 to 11 years is also the most sensitive and critical stage for RD's screening. From the personality viewpoint, the chosen range aims to avoid transition between the first years of life and puberty, once that developmental variations might affect results.

The participating children successfully completed an average of 3 years of schooling (SD $=1.22$, Min $=1$ and $\operatorname{Max}=6)$ and showed a low scholar failure $(\mathrm{M}=.24, \mathrm{SD}=.70, \mathrm{Min}$ $=0$ and $\operatorname{Max}=4)$.

In this study, in addition to children, also participated the majority of their respective parents: 83 fathers, aged from 23 to 59 years $(M=41.62$ and $\mathrm{SD}=6.90)$ and 86 mothers, aged from 25 to 49 years $(M=38.49$ and $\mathrm{SD}=4.84)$. At least one of the parents of each child participated in this study.

\section{Instruments}

In an attempt to operationalize the variables under study, several instruments were used.

\section{General Information: SDQ}

A specific socio-demographic questionnaire (SDQ) was developed in order to collect general information about parents (age, education, occupational status, marital status and socioeconomic status-SES) and about each participating child (gender, age, education, number of academic failures, number of siblings, general health problems, neurological problems and visual or hearing difficulties).

\section{Intellectual Level: CPM}

Intellectual level was controlled by Raven Colored Progressive Matrices (CPM, developed by Raven et al. 1947 and adapted to Portuguese population by Simões 1995). Internal consistency analyses conducted in this research confirmed very good values $(\alpha=.940, \mathrm{M}=29.53, \mathrm{SD}=$ 5.75).

\section{Parenting Styles: EMBU-C and EMBU-P}

EMBU-C (Canavarro and Pereira 2007a; Castro et al. 1993) assesses children's perception about PS using 32 items with 4 points Likert scales where 1 corresponds to "No, never" and 4 to "Yes, always". Factorial structure of the Portuguese version replicates the original version with three factors: (a) Emotional Support (14 items, verbal and physical emotional support from parents, parental acceptance and physical/psychological availability); (b) Rejection (17 items, hostility or verbal/physical aggression and non-acceptance by parents); and (c) Attempt to Control (11 items, intentions and actions to control children's behaviour). In the study of Canavarro and Pereira (2007a), acceptable Cronbach's alphas were obtained (between .62 and .85) and the same applies to this research $(.51 \leq \alpha \leq .88)$.

EMBU-P (Canavarro and Pereira 2007b; Castro et al. 1990) is an instrument that aims to assess parents' self-perceptions regarding their children, with 42 items using 4 points Likert scales ranging from "No, never" to "Yes, always" and organized in the same three dimensions (14 items on Emotional Support, 17 items on Rejection and 11 items on Attempt to Control). Factorial structure of EMBU-P's Portuguese version also evidences a three-factor structure, 
roughly equivalent to the original version (Canavarro and Pereira 2007b). Regarding internal consistency, acceptable Cronbach's alphas were found (between .58 and .82).

In order to avoid confusion between data emerging from the several instruments used to assess PS (EMBU-C and EMBU-P), by convention, we have used the following terminology: "children's perceptions" to refer to data from EMBU-C and "parents' representations" to refer to data from EMBU-P.

\section{Psychopathology: CBCL}

Child Behaviour Checklist (CBCL) consists in a set of instruments proposed by Achenbach (1991) in order to assess behavioural and emotional problems and competencies among children and adolescents based on information provided by parents or respective substitutes. Portuguese version of CBCL—named the Inventário do Comportamento da Criança para Pais (Child Behaviour Inventory for Parents) was administered. Items, rated on a scale ranging from 0 (not true) to 2 (very often true or real), are split into two sections: 20 questions regarding individual skills and 120 items regarding behavioural problems.

According to Fonseca et al. (1994), items were carefully chosen to represent most frequent children's pathologies and show high correlations with other questionnaires completed by parents regarding general psychopathology, like Conners' Scales, Rutter's Scale and Revised Behaviour Problems Checklist. Studies in several cultures revealed good internal consistency $(.61 \leq \alpha \leq .83)$ and the same applies either to English version $(.56 \leq \alpha \leq .75)$ or present study $(.55 \leq \alpha \leq .94)$, except for subscale of somatic complaints which was removed $(\alpha=.43)$.

\section{Reading Processes: PROLEC-R}

To assess RP we used the PROLEC-R, Bateria de Avaliação dos Processos Leitores-Revista (Reading Processes' Assessment Battery-Revised), developed by Cuetos et al. (2007), whose adaptation to Portuguese population is in course by Figueira et al. (in press). PROLEC$\mathrm{R}$ is an individual test, based in the cognitive model of reading comprehension processes, for children aged 6-12 years. It involves nine tasks whose application time varies from 20 to 40 min: (a) Identification of Letters, (b) Same-Different, (c) Words Reading, (d) Pseudowords Reading, (e) Grammatical Structures, (f) Punctuation, (g) Sentences Comprehension, (h) Text Comprehension and (i) Listening. The main aim of PROLEC-R is to assess the reading components which are affected in children unable to learn how to read (Figueira et al. 2011). According to his Spanish editor, PROLEC-R is one of the most important references in reading assessment in Spain (Cuetos et al. 2007). Regarding internal consistency, Cuetos et al. (2007) obtained satisfactory values $(.48 \leq \alpha \leq .79)$, that were overcome in the present study $(.62 \leq \alpha \leq .97)$.

\section{Procedures}

After obtained written consent and once controlled all general inclusion criteria, children and parents were assessed trough previously described instruments.

A preliminary analysis by Kolmogorov-Smirnov test $(p>.05)$, Shapiro-Wilk test $(p>$ .05 ) and Normal QQ Plots (deviations between -2 and +2 ) has shown that the variables does not significantly deviate from normal distribution.

Hypotheses were tested using a multiple hierarchical linear regression model. Model application requests were checked regarding statistical Tolerance $(T>.1)$ and VIF $(V I F<$ 
$10)$ in order to avoid multicollinearity effects. According Durbin-Watson's statistic $(d \approx 2)$, errors are random and independent. Significant effects were considered when $p<.05$.

\section{Results}

In linear hierarchical regression analysis, five models (blocks) were considered: Model 1, individual factors (age, gender, education and intellectual level); Model 2, family factors (adds family's socio-demographic characteristics such as SES, education, parents' marital/occupational status and number of siblings); Model 3 (CBCL), adds CBCL's indexes of psychopathology; Model 4, which includes EMBU-P's subscales and lastly, Model 5 becomes complete with the addition EMBU-C's subscales.

According to Table 1: (a) all PROLEC-R's reading scales are explained by individual factors; (b) the majority is explained by family factors and; (c) some scales (Pseudowords Reading, Sentences Comprehension and Listening) are also explained by CBCL's indexes of psychopathology (Table 1).

As seen in Tables 1 and 2 and according our hypothesis, even when considering all these factors, perceptions of children about PS still can explain the variance of Grammatical Structures, Sentences Comprehension and Listening.

\section{Children's Perceptions About Maternal PS}

Grammatical Structures: An analysis of regression coefficients and their statistical significance identified the following significant predictors of Grammatical Structures: intellectual level $(\beta=.547, t=3.368, p=.002)$, parents' marital status $(\beta=.416, t=2.728, p=$ $.009)$, father's education $(\beta=.401, t=2.740, \quad p=.009)$, Opposition/Immaturity $(\beta=.326, t=2.163, p=.037)$, Aggression $(\beta=.312, t=2.311, p=.026)$, Hyperactivity/Attention $(\beta=-.750, t=-3669, p=.001)$, Isolation $(\beta=-.356=$, $t=-2877, p=.006)$ and EMBU-C's Rejection $(\beta=.378, t=3.427, p=.001)$.

Sentence Comprehension: An analysis of regression coefficients and their statistical significance identified the following significant predictors of Sentence Comprehension: age

Table 1 Reading difficulties' statistical variance explanation through parenting styles ( $p$ values)

\begin{tabular}{lllllll}
\hline Dependent variables & Individual factors & Family factors & CBCL & EMBU-P & EMBU-C \\
\cline { 3 - 6 } & & & & & Mother & Father \\
\hline Identification of letters & .000 & .015 & - & - & - & - \\
Same-different & .000 & - & - & - & - & - \\
Words reading & .000 & - & - & - & - & - \\
Pseudowords reading & .000 & .005 & .011 & - & - & - \\
Grammatical structures & .000 & .002 & - & - & .006 & .001 \\
Punctuation & .006 & - & - & - & - & - \\
Sentences comprehension & .000 & .000 & .001 & - & .000 & .000 \\
Text comprehension & .000 & .000 & .017 & - & - & - \\
Listening & .000 & .006 & .025 & .020 & - & .014 \\
\hline
\end{tabular}




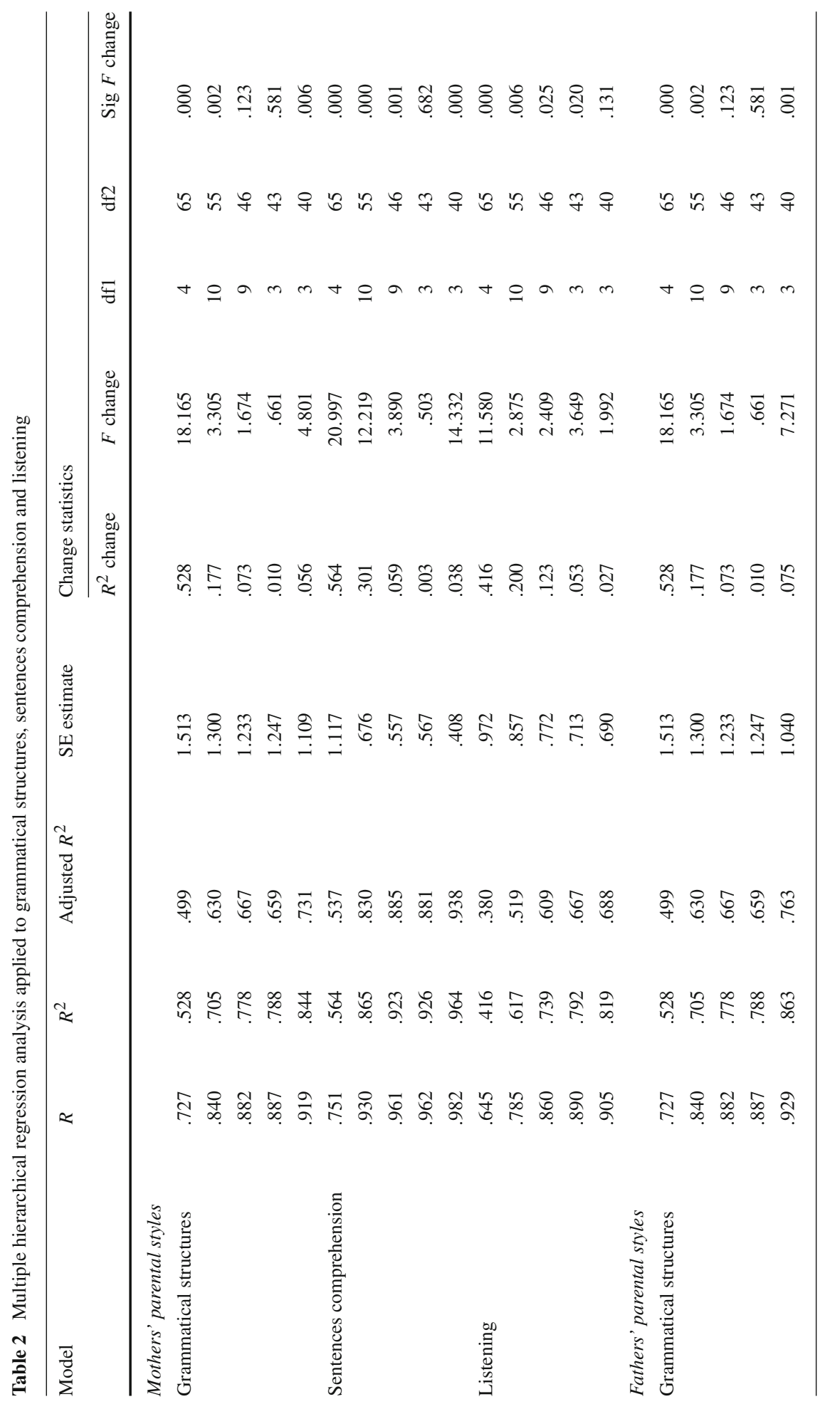




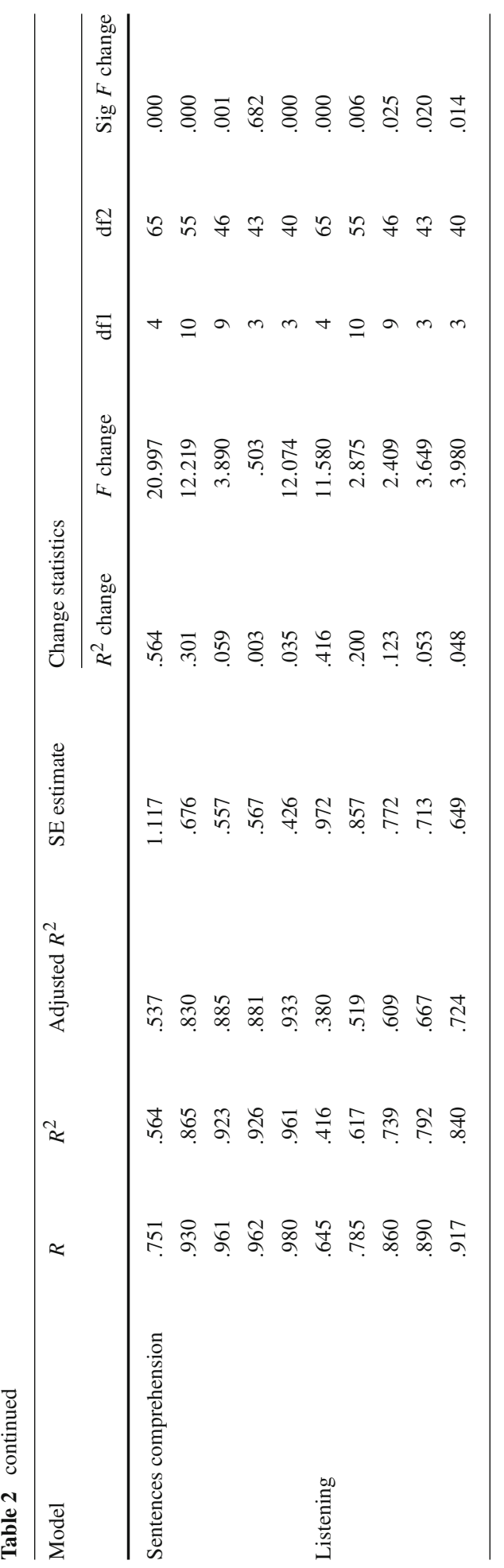

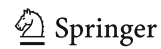


$(\beta=-.373, t=-5401, p=.000)$, education $(\beta=.445, t=6.255, p=.000)$, intellectual level $(\beta=.250, t=3.216, p=.003)$, father's $\operatorname{SES}(\beta=.431, t=$ $8.664, p=.000)$, parents' marital status $(\beta=.371, t=5.088, p=.000)$, father's education $(\beta=.196, t=2.798, p=.008)$, Opposition/Immaturity $(\beta=.168, t=$ 2.324, $p=.025)$, Aggression $(\beta=-.249, t=3.848, p=.000)$, Social Problems $(\beta=.120, t=2.032, p=.049)$, Anxiety $(\beta=-.239, t=3.210, p=.003)$, EMBU-P's Rejection $(\beta=.155, t=2.072, p=.045)$ and EMBU-C's Emotional Support $(\beta=.332, t=6.288, p=.000)$.

Listening: An analysis of regression coefficients and their statistical significance identified the following significant predictors of Listening: education $(\beta=.340, t=2.099, p=$ $.042)$, mother's SES $(\beta=-.682, t=-3726, p=.001)$, parents' marital status $(\beta=.363, t=2.176, p=.035)$, father's education $(\beta=.414, t=2.586, p=.013)$, Depression $(\beta=-.559, t=-2.667, p=.011)$ and EMBU-P's Emotional Support $(\beta=.383, t=2.844, p=.007)$.

As previously described, PS could not predict any other PROLEC-R's scales, reason why we don't mention the specific contribution of each predictor for remain scales.

\section{Children's Perceptions About Father's PS}

Grammatical structures: An analysis of regression coefficients and their statistical significance identified the following significant predictors of Grammatical Structures: age $(\beta=.321, t=2.389, p=.022)$, intellectual level $(\beta=.541, t=3.570, p=.001)$, parents' marital status $(\beta=.457, t=3.206, p=.003)$, number of siblings of the child $(\beta=-.242, t=-2242, p=.031)$, father's education $(\beta=.420, t=3.047, p=.004)$, Aggression $(\beta=.342, t=2.686, p=.010)$, Hyperactivity/Attention $(\beta=-.548, t=$ $-3138, p=.003)$, Isolation $(\beta=-.285, t=-2424, p=.020)$ and EMBU-C's Rejection $(\beta=.480, t=4.210, p=.000)$.

Sentence Comprehension: An analysis of regression coefficients and their statistical significance identified the following significant predictors of Sentence Comprehension: age $(\beta=-.322, t=-4493, p=.000)$, education $(\beta=.396, t=5.120, p=.000)$, intellectual level $(\beta=.245, t=3.033, p=.001)$, father's SES $(\beta=.471, t=8.721, p=.000)$, parents' marital status $(\beta=.401, t=5.284, p=.000)$, number of siblings $(\beta=$ $-.134, t=2.319, p=.026)$, father's education $(\beta=.204, t=2.775, p=.008)$, Aggression $(\beta=-.220, t=3.245, \mathrm{p}=.002)$, Social Problems $(\beta=.138, t=2.284, \mathrm{p}=.028)$, Anxiety $(\beta=-.236, t=3.192, p=.003)$, EMBU-P's Rejection $(\beta=.167, t=$ $2.152, p=.038)$ and EMBU-C's Rejection $(\beta=.357, t=5.881, p=.000)$.

Listening: An analysis of regression coefficients and their statistical significance identified the following significant predictors of Listening: education $(\beta=.392, t=2.500, p=$ $.017)$, mother's SES $(\beta=-.654, t=-3.767, p=.001)$, father's occupational status $(\beta=.323, t=2.131, p=.039)$, parents' marital status $(\beta=.409, t=2.660, p=.011)$, number of siblings $(\beta=-.394, t=-3379, p=.002)$, father's education $(\beta=.489, t=$ $3.289, p=.002)$, Opposition/Immaturity $(\beta=.443, t=2.991, p=.005)$, Aggression $(\beta=.307, t=2.240, p=.031)$, Depression $(\beta=-.525, t=-2702, p=.010)$, Social Problems $(\beta=-.298, t=-2436, p=.019)$, EMBU-P's Emotional Support $(\beta=$ $.524, t=4.047, p=.000)$ EMBU-C's Emotional Support $(\beta=-.286, t=-2348, p=$ $.024)$ and Rejection $(\beta=.278, t=2.261, p=.029)$.

As previously described, PS could not predict any other PROLEC-R's scales, reason why we don't mention the specific contribution of each predictor for remain scales. 


\section{Discussion}

Several authors (e.g., Alexander and Slinger-Constant 2004; Cuetos et al. 2007; GarcíaMadruga 2006; Shaywitz 2003; Viana and Teixeira 2002) conceive RP as divided into at least two major components: decoding, which results in immediate recognition of words, and comprehension related to its meaning.

To Cuetos et al. (2007), a proper reading requires, first of all, a rapid and automatic recognition of alphabet letters, a step that authors consider to be basic and fundamental and that is shared in all reading models. After this step there are a set of lexical processes involving particularly word's visual recognition. According to the same authors it is exactly in this step that major differences appear between dyslexics and regular readers. However, although individual words can activate meanings stored in memory, they cannot transmit messages by themselves (Cuetos et al. 2007), reason why the authors argue that reading cannot be reduced to simple word recognition being necessary to consider syntactic and semantic processes.

Difficulties found at syntactic processes' level may be due in particular to a misinterpretation of punctuation or a difficulty in syntactic structures' interpretation (Cuetos et al. 2007): Many children present difficulties in use of structurally complex sentences, such as passive voice.

In order to an adequate reading comprehension it is necessary to integrate information within semantic memory, a procedure that occurs at the so-called semantic processes' level (Cuetos et al. 2007). According to García-Madruga (2006), semantic processes are composed at least by three sub-processes: (a) extraction of meaning, which is basically the assignment of the agent, the object, the place and the time of action, answering briefly to questions like "who did what, where and when"; (b) memory integration, and (c) inferential processes. Considering that in everyday life, we rarely find short or isolated sentences as they are usually organized in a text, meaning extraction can be uninformative, reason why it is necessary to move forward and assess texts comprehension. We can find in literature several cases in which subjects can read words and texts without understanding any information, a condition that is known as hyperlexia (Castles et al. 2006; Siegel 1989).

Notwithstanding mnesic integration is fundamental, this cannot be seen as the ultimate goal of understanding, since prior information should enrich knowledge and develop thinking. According Cuetos et al. (2007), inferential processes are closely related either with meaning extraction (since texts are often interrelated and it is possible to extract its meaning after establishing appropriate relationships), either with mnsesic integration (since it is necessary to infer which stored information is necessary to integrate).

Fletcher (2009) recognizes that RD depend on a combination of environmental and psychosocial factors. Knowing that children whose parents early encourage them to read tend to have better phonological awareness and better performance in reading tasks (Morais 1994), it was proposed the hypothesis that children's representations about PS would contribute to the explanation of the statistical variance of RD.

Based on previously presented results it appears that, even when controlling the effect of individual and familiar variables and child psychopathological indexes, PS play a significant role in the explanation of higher (syntactic and semantic) RP. Thus, PS do not seem to relate to peripheral perceptive aspects (like identification of letters) or even with lexical processes (core of main theories about dyslexia-e.g., Démonet et al. 2004; Ramus 2001; Vellutino et al. 2004). Briefly, and considering the classification of Shaywitz (2003), it can be said that PS have proved to be important for the explanation of reading comprehension processes. 
These results do not jeopardize the dominant theory according to which RD are mainly due to poor phonological coding, instead emphasizes that reading should not be seen as a mere process of decoding. Moreover, although individual factors are essential, especially in early stages of reading models, PS seem to be relevant in the explanation of higher comprehension processes. Considering that, based on recommendations for reading disabled individuals' rehabilitation (cfr. Cuetos et al. 2007), when compared with decoding, comprehension involves a greater integration of information, these results seem to make sense and can be easily accepted.

The fact that PS explain Grammatical Structures' scores but not Punctuation's could be associated with task's complexity: Reader's ability to syntactically process sentences with different Grammatical Structures (88\% of success) has a different complexity than Punctuation (74\% of success). The same reasoning seems to apply to semantic processes in which PS explain Sentences Comprehension (92.44\% of success) and Listening $(99.25 \%$ of success), but not Texts Comprehension (66.81\% of success). In Listening tasks, children only hears the texts that are read to them while Sentences Comprehension tasks already involves reading of single/isolated sentences and Texts Comprehension involves reading of several sentences grouped/organizes in texts.

Therefore, it seems natural that regression line for Listening assume a positive inclination relative to EMBU-P's Emotional Support subscale and EMBU-C's father Emotional Support subscale, which indicates that the higher is both parents and children emotional support's representation, the better is performance in Listening tasks. Nevertheless, it should be noted that (a) regression lines for Grammatical Structures, Sentences Comprehension and Listening assume positive slopes for EMBU-C's fathers Rejection subscale, which suggests that the greater are the feelings of paternal rejection, the better is children's performance in Grammatical Structures, Sentences Comprehension and Listening and (b) regression line for Sentences Comprehension assume a positive slope for EMBU-P's Rejection scale, suggesting that the more parents adopt an attitude of rejection towards their child, the higher is the children's performance in Sentences Comprehension tasks.

These results can suggest that reading comprehension's processes would benefit both either by situations in which parents adopt a support stance either by cases in which parents adopt an attitude of non-acceptance of the child. Although the first case could be easily understand, the fact that rejection may lead to better performance on reading tasks, would perhaps lead us to consider a proactive stance from children that could hardly be generalized, lacking for a further deepening.

Despite results confirm underlying hypothesis for comprehension processes, we should recognize the importance of family and specially individual factors to explain global results' variance that should not, therefore, be neglected in any explanatory model of RD.

It is also interesting to note the fact that, according to results, psychopathology presents itself an explanatory capacity for semantic processes (Sentences Comprehension, Text Comprehension and Listening) as well as for a syntactic process (Pseudowords Reading). Among several psychopathology indexes, we highlight Opposition/Immaturity (with explanatory power for Sentences Comprehension), Aggression (with explanatory power for Sentences and Texts Comprehension), Anxiety (with explanatory power for Pseudowords Reading and Sentences Comprehension), Social Problems (with explanatory power for Sentences Comprehension), Obsessive/Schizoid (with explanatory power for Sentences Comprehension) and Depression (with explanatory power for Listening), which seem to be congruent with Knivsberg and Andreassen (2008), Sundheim and Voeller (2004), Salyer et al. (1991). 
The results also seem to be in agreement with the model of Fletcher (2009) which assumes learning disabilities, including RD, as resulting from several factors (neurobiological, cognitive, psychosocial/behavioral and environmental).

\section{Conclusion}

Results partially confirm the hypothesis that children's representations about PS contributes to the explanation of RD. As previously discussed, even controlling the effect of individual variables, family factors and indexes of child psychopathology, PS play an important role for the explanation of higher RP, situated at syntactic and semantic level. This suggests that PS do not relate to more peripheral perceptive matters (e.g., identification of letters) or even with lexical processes - that allow the diagnosis and classification of central dyslexia) but with superior matters alluding the comprehension of written information writing, which reinforces and clarifies the importance of PS in RP and therefore in RD.

It is considered that these results play a crucial role in future direction of research about $\mathrm{RD}$ (so far focused on lexical processes, and lately girded to child's own characteristics) as well as in rehabilitation strategies that so often ignore syntactic and semantic processes as well as parental figures.

Despite the efforts of some authors (e.g., Carreteiro 2007; Figueira et al. in press; Sucena and Castro 2011) to develop, in late years, new tools for assessing reading adapted to the Portuguese population, compared with other countries' psychometric framework, there is still little evidence in order to a proper assessment of RD reason why it is considered urgent to develop new tests and to adapt to European Portuguese context other instruments that may already be available in other countries. Further studies are invited, through different instruments, both in terms of RP' assessment and PS' assessment, to eventually confirm our findings.

\section{References}

Achenbach, T. M. (1991). Integrative guide to the 1991 CBCL/4-18, YSR, and TRF profiles. Burlington, VT: University of Vermont, Department of Psychology.

Alexander, A., \& Slinger-Constant, A.-M. (2004). Current status of treatments for dyslexia: Critical review. Journal of Child Neurology, 19(10), 744-758.

Al-Yagon, M. (2007). Socioemotional and behavioral adjustment among school-age children with learning disabilities: The moderating role of maternal personal resources. The Journal of Special Education, 40(4), $205-217$.

Areepattamannil, S. (2010). Parenting practices, parenting style, and children's school achievement. Psychological Studies, 55(4), 283-289.

Bus, A. G., van IJzendoorn, M. H., \& Pellegrini, A. D. (1995). Joint book reading makes for success in learning to read: A meta-analysis on intergenerational transmission of literacy. Review of Educational Research, $65,1-21$.

Canavarro, M., \& Pereira, A. (2007a). A perceção dos filhos sobre os estilos educativos parentais: A versão portuguesa do EMBU-C. RIDEP, 24(2), 193-210.

Canavarro, M. C., \& Pereira, A. I. (2007b). A avaliação dos estilos parentais educativos na perspectiva dos pais: A versão portuguesa do EMBU-P. Psicologia: Teoria Investigação e Prática, 2, 271-286.

Carreteiro, R. (2007). Elaboración de una prueba para evaluar da dyslexia. Trabajo de Grado, Facultad de Psicologia, Universidade de Salamanca.

Castles, A., Bates, T., \& Coltheart, M. (2006). John Marshall and the developmental dyslexias. Aphasiology, 20(9), 871-892. doi:10.1080/026870300600738952.

Castles, A., \& Coltheart, M. (2004). Is there a causal link from phonological awareness to success in learning to read? Cognition, 91, 77-111. 
Castro, J., Toro, L., Van der Ende, J., \& Arrindell, W. (1993). Exploring the feasibility of assessing perceived parental rearing. Journal of Social Psychiatry, 39, 47-57.

Castro, J., Toro, J., Van der Ende, J., Arrindell, W. A., \& Puig, J. (1990). Perceived parental rearing styles in Spanish adolescents, children and parents: The new forms of the EMBU. In C. N. Stefanis, C. R. Solsatos, \& A. D. Ravavilas (Eds.), Psychiatry: A word perspective (Vol. 4, pp. 340-344). Amsterdam: Elsevier Science.

Chan, T. W., \& Koo, A. (2010). Parenting style and youth outcomes in the UK. European Sociological Review. doi:10.1093/esr/jcq013.

Cripps, K., \& Zyromski, B. (2009). Adolescents' psychological well-being and perceived parental involvement: Implications for parental involvement in middle schools. RMLE Online: Research in Middle Level Education, 33(4).

Cuetos, F., Rodríguez, B., Ruano, E., \& Arribas, D. (2007). PROLEC-R: Batería de Evaluación de los Procesos Lectores, Revisada. Madrid: TEA Ediciones.

Dehaene, S. (2007). Les Neurones de la lecture. Paris: Ddiles-Jacob.

Démonet, J.-F., Taylor, M., \& Chaix, Y. (2004). Developmental dyslexia. The Lancet: Seminar, 363(9419), 1451-1460.

Ewnetu, S., \& Fisseha, M. (2008). The teacher relationship behavior and parenting style correlates of students' scholastic achievement at grade seven English. Ethiopian Journal of Education and Science, 4(1), 39-50. doi:10.4314/ejesc.v4i1.42991.

Ferreiro, E., \& Teberosky, A. (1986). Psicogênese da Língua Escrita. Porto Alegre: Artes Médicas.

Figueira, A. P., Lopes, I. M., Serra, M. A. \& Almeida, A. C. (2011). PROLEC-R-Evaluation of processes of reading computerized version. In ICT for language learning, international conference, Florence, Italy.

Figueira, A. P., Lopes, I., \& Almeida, M. (in press). PROLEC-R: Bateria de Avaliação dos Processos de Leitura-Revista. Lisboa: CEGOC.

Fitzgerald, L., Spiegel, D., \& Cunningham, J. (1991). The relationship between parental literacy level and perceptions of emergent literacy. Journal of Reading Behavior, 23(2), 20.

Fletcher, J. (2009). Dyslexia: The evolution of a scientific concept. Journal of the International Neuropsychological Society, 15, 501-508.

Fonseca, A., Simões, A., Rebelo, J., Ferreira, A., \& Cardoso, F. (1994). Um inventário de competências sociais e problemas do comportamento em crianças e adolescentes-O Child Behaviour Checklist de Achenbach (CBCL). Psychologica, 12, 55-78.

Gallagher, A., Frith, U., \& Snowling, M. (2000). Percursor of literacy delay among children at genetic risk of dyslexia. Journal of Child Psychology and Psychiatry, 1(2), 203-213.

García-Madruga, J. (2006). Lectura y conocimiento. Barcelona: Paidós.

Green, R.-J. (1989). "Learning to learn" and the family system: new perspectives on underachievement and learning disorders. Journal of Marital \& Family Therapy, 15, 187-203. doi:10.1111/j.1752-0606.1989. tb00798.x.

Harmer, W., \& Alexander, J. (1978). Examination of parental attitudes within the diagnostic intervention process. Journal of Learning Disabilities, 11(9), 590-593. doi:10.1177/00222194780110092.

Jacob, J. (2011). An examination of the relationship between intelligence and state achievement test scores in relation to the perceived parental expectations, involvement and parenting style of middle school students. Dissertation Abstracts International Section A: Humanities and Social Sciences, 71(10-A), 3529.

Jeynes, W. H. (2007). The relationship between parental involvement and urban secondary school student academic achievement: A meta-analysis. Urban Education, 42(1), 82-110. doi:10.1177/0042085906293818.

Kissinger, A. (2004). The need for emergent literacy events in schools. Knowledge Quest, 33(2), 58-60.

Knivsberg, A.-M., \& Andreassen, A. (2008). Behaviour, attention and cognition in severe dyslexia. Nordic Journal of Psychiatry, 62(1), 59-65.

Mendoza, C. (2013). Parental involvement and student motivation: A quantitative study of the relationship between student goal orientation and student perceptions of parental involvement among 5th grade students. Dissertation Abstracts International Section A: Humanities and Social Sciences, 74(6-A)(E).

Morais, J. (1994). L’Art de Lire. Editions Odile Jacob. Paris. (Tradução portuguesa: A Arte de Ler. Psicologia Cognitiva da Leitura. Edições Cosmos, 1997).

Morais, J., Cary, L., Alegria, J., \& Bertelson, P. (1979). Does awareness of speech as a sequence of phones arise spontaneously? Cognition, 7, 323-331.

Narita, K., Takei, Y., Suda, M., Aoyama, Y., Uehara, T., Kosaka, H., et al. (2010). Relationship of parental bonding styles with gray matter volume of dorsolateral prefrontal cortex in young adults. Progress in Neuro-Psychopharmacology \& Biological Psychiatry, 34(4), 624-631.

Pacheco, A., Reis, A., Araújo, S., Inácio, F., Petersson, K., \& Faísca, L. (2014). Dyslexia heterogeneity: Cognitive profiling of Portuguese children with dyslexia. Reading and Writing, 26, 1529-1545. doi:10. 1007/s11145-014-9504-5. 
Payne, A. C., Whitehurst, G. J., \& Angell, A. L. (1994). The role of home literacy environment in the development of language ability in preschool children from low-income families. Early Childhood Research Quarterly, 9, 427-440.

Ramus, F. (2001). Outstanding questions about phonological processing in dyslexia. Dyslexia, 7, 197-216.

Raven, J., Raven, J. C., \& Court, J. H. (1947, updated 2004) Manual for Raven's progressive matrices and vocabulary scales. San Antonio, TX: Harcourt Assessment.

Reese, E., \& Cox, A. (1985). Quality of adult book reading affects children's emergent literacy. Developmental Psychology, 35(1), 20-28.

Salyer, K., Holmstrom, R., \& Noshpitz, J. (1991). Learning disabilities as a childhood manifestation of severe psychopathology. American Journal of Orthopsychiatry, 61(2), 230-240.

Scarborough, H. S., \& Dobrich, W. (1994). On the efficacy of reading to preschoolers. Developmental Review, $14,245-302$.

Senechal, M. (2000). A naturalistic study of the links between storybook reading and vocabulary development in preschool children. Enfance, 52, 169-186.

Shaywitz, S. (2003). Dyslexia: A new and complete science-based program for reading problems at any level. São Paulo: Tradução portuguesa Artmed.

Siegel, L. (1989). IQ is irrelevant to the Definition of Learning Disabilities. Journal of Learning Disabilities, 22(8), 469-478.

Simões, M. (1995). O Teste das Matrizes Progressivas Coloridas de Raven. In L. Almeida, M. Simões, \& M. Gonçalves (Eds.), Provas Psicológicas em Portugal (pp. 1-18). Braga: Associação dos Psicólogos Portugueses.

Sucena, A., \& Castro, S. L. (2011). PROLEPE: Prova de Leitura em Português Europeu. Lisboa: CEGOC.

Sundheim, S., \& Voeller, K. (2004). Psychiatric implications of language disorders and learning disabilities: Risks and management. Journal of Child Neurology, 19, 814-826.

Viana, F., \& Teixeira, M. M. (2002). Aprender a Ler: Da aprendizagem informal à aprendizagem formal. Porto: Edições Asa.

Vellutino, Fletcher, Snowling, \& Scanlon, (2004). Specific reading disability (dyslexia): What have we learned in the past four decades? Journal of Child Psychology and Psychiatry, 45(1), 2-40.

Williams, W. (2008). The relationship between parenting practices, socioeconomic status, and ethnicity to the academic achievement of high school students. Retrieved from http://www.allfreeessays.com/essays/ Relationship-Between-Parenting-Practices-Soeconomic-Status/11502.html

Zellman, G., \& Waterman, J. (1998). Understanding the impact of parent school involvement on children's educational outcomes. The Journal of Educational Research, 91(6), 370-380. 